\title{
QUANTIFICATION OF THE SINUSOIDAL TRAJECTORY IN TISSUE MASS AND CONDITION INDICES OF A BIVALVE (EGERIA RADIATA) IN THE CROSS RIVER, NIGERIA*
}

\author{
LAWRENCE ETIM, THOMAS BREY and WOLF ARNTZ \\ Alfred Wegener Institule for Polar and Marine Research, Postfach 120161, D-27515 Bremerhaven, Germany
} (Received 1 May 1996; accepted 30 August 1996)

\begin{abstract}
Variation in monthly values of dry tissue mass (DTM) and two different types of condition indices of the bivalve Egeria radiata (Lamarck, 1804) was studied for 32 consecutive months. To quantify the seasonal trajectory of variation these data were fitted to one- and two-comparment sinusoidal models; and also to a quadratic, cubic and quartic models. The cyclic events in the variation of the DTM and both indices of condition were adequately described by the one-compartment sinusoidal model whose parameters are biologically interpretable. The fit of the data is progressively improved as one moves from the quadratic through the cubic to the quartic model whose fit was best. Although biological meaning could be found for the one-compartment sinusoidal model, the biological meaning of the coefficients of the parabolic-based models are obscure. Multiple regression analysis shows that of all the four environmental parameters (temperature, salinity, $\mathrm{pH}$ and phytoplankton) tested, temperature has the greatest effect on DTM and one of the condition indices, while $\mathrm{pH}$ has the greatest impact on the other condition index. This implies that the two indices are not only intrinsically different, but that they respond to different sets of factors. Inter- and intra-specific comparison of the many recommended 'standard' indices of condition found in the literature, especially with regard to their innate sensitivity to seasonal variation in internal (e.g. state of gravidity) and external (physicochemical parameters of water) factors is necessary.
\end{abstract}

\section{INTRODUCTION}

Grave (1912) was probably the first to utilise a ratio (100*meat volume/shell cavity volume) to express the 'fatness' of a bivalve species. Today, there are many such ratios under the generic name of condition index. Their general characteristics have been reviewed by Mann (1978) and Lucas \& Beninger (1985) while Lawrence \& Scott (1982), Davenport \& Chen (1987), Crosby \& Gale (1990) and Rainer \&
Mann (1992) compared various methods of computation and standardisation.

Seasonal variations in the tissue mass or any condition index of many bivalves follow a wave form or a closely related pattern. Such patterns have been found useful for economic purposes in describing the period when harvesting could give maximum meat yields (Nair \& Nair, 1987), for ecological purposes in elucidating the spawning period (Etim, 1990), and for the biomonitoring of pollution and environmental stress (Marcus, Scott \& Heizer, 1989), and disease condition (Sastry, 1979). Often, the description of the seasonal variation in the condition index and tissue mass of bivalves has been qualitative. Fitting a periodic regression model (Batschelet, 1981; Loesch \& Evans, 1994) to such data could confer a statistical predictive power and also render it more amenable to further quantitative analysis. Fitting a linear regression to a scatter plot enables one to compare quantitatively two or more sets. Equally, fitting a periodic regression to data on seasonal patterns of condition index of bivalve could serve as a basis in quantitative comparison of the nature of the cyclic events of the bivalve condition. The aim of this work is to explore the mathematical plausibility of fitting a basic sinusoidal, two compartment sinusoidal, and polynomial models to the data on the monthly variation in tissue mass and condition index of the bivalve Egeria radiata (Lamarck, 1804).

Egeria radiata is of both ecological and economic importance. It is a fresh water donacid bivalve endemic to the West African subregion. It is a gonochoristic species which spawns once in a year during the peak of the rainy season (June to October). The species is abundant in many large rivers e.g. Volta (Ghana), Sanaga (Cameroon), and Cross (Nigeria) rivers. It supports a rich and thriving artisanal fisheries wherever it is found. Several 
aspects of its biology have been documented e.g. general biology and gross anatomy (Purchon, 1964), population dynamics and fisheries (Etim \& Brey, 1994; Moses, 1990), and reproduction cycle (Etim, 1996). In this study, the species is used in demonstrating the mathematical feasibility and utility of adopting a quantitative approach in elucidating the seasonal patterns in variation of tissue mass and condition indices of bivalves.

\section{MATERIALS AND METHODS}

Clams were obtained from artisanal fishermen in the Cross River ( $\sim$ Long. $8^{\circ} 4^{\prime} \mathrm{E}$, Lat. $\left.5^{\circ} 11^{\prime} \mathrm{N}\right)$, Nigeria. Monthly samples of 10 to 20 specimens whose lengths (maximum anterio-posterior dimension) ranged between $70.0 \mathrm{~mm}$ and $73.0 \mathrm{~mm}$ were bought between February 1987 and September 1989. The shell-free dry mass of each specimen was determined by oven-drying the tissue at $60^{\circ} \mathrm{C}$ for 72 hours. The monthly average shell-free dry mass was then plotted against time to give the pattern of seasonal variation from which the spawning season of the species could be deduced. Data on the monthly variation in bottom water temperature, salinity, phytoplankton counts, and $\mathrm{pH}$ were as recorded in Etim (1990) and Etim \& Taege (1993).

First, a multiple regression of the dry tissue mass (DTM) against temperature (temp), salinity (sal), phytoplankton count (phyto), and $\mathrm{pH}$ was computed in order to assess the relative importance of the influence of each of these on the dependent variable.

$$
\begin{array}{r}
\text { DTM }=a+b_{1} \text { lemp }+ \\
\quad b_{2} \text { sal }+b_{3} \text { time }+b_{4} \text { phyto }+b_{5} \text { pH }
\end{array}
$$

where $a$ is the constant and $b$ values are the multiple regression coefficients.

The following condition indices were computed:

(i) Dry tissue mass/Dry shell mass

This is the index recommended by Lucas \& Beninger (1985) and is herein referred to as condition index-1 (Cl-1).

(ii) 1000 (Dry tissue mass/Shell cavity volume)

This is the index recommended by Crosby \& Gale (1990) and is herein referred to as condition index-2 (Cl-2).

To quantify the cyclic event, nonlinear regression models were iteratively fitted to the monthly data on DTM using the Quasi-Newton algorithm (Press, Flannery, Teukolsky \& Velting, 1986) available on Systat (1992). The Quasi-Ncwton procedure (which yielded the same results as the Simplex algorithm) was preferred because it was faster.

The basic sinusoidal model used is

$$
D T M=M_{0}+A \cos 2 \pi t+B \sin 2 \pi t
$$

where DTM is the monthly dry tissue mass (=shell free dry mass), $t$ is the time of sample collection expressed in years, $M_{0}$ is the mesor, while $A$ and $B$ are the model constants which were determined empirically.

In its alternative form, it follows that

$$
D T M=M_{0}+h \cos 2 \pi\left(t=t_{0}\right)
$$

where $h$ is the amplitude of sinusoidal variation, and $t_{0}$ is the acrophase.

The two component sinusoidal model takes the form $\mathrm{DTM}=\mathrm{M}_{\mathrm{o}}+\mathrm{A}_{1} \cos 2 \pi \mathrm{t}+$

$$
B_{1} \sin 2 \pi t+A_{2} \cos 4 \pi t+B_{2} \sin 4 \pi t
$$

The dependent variable in equations 2,3 and 4 were in turn replaced with $\mathrm{Cl}-1, \mathrm{Cl}-2$.

For further exploratory purposes, the data on DTM was also fitted to a basic quadratic model.

$$
\mathrm{DTM}=\mathrm{M}_{\mathbf{0}}+\mathrm{AT}+\mathrm{Bt}^{2}
$$

The addition of an extra term would yield cubic and quartic models successively as follows:

$$
\begin{aligned}
& \text { DTM }=\mathrm{M}_{0}+\mathrm{At}+\mathrm{Bt}^{2}+\mathrm{Ct}^{3} \\
& \text { DTM }=\mathrm{M}_{\mathbf{0}}+\mathrm{At}+\mathrm{Bt}^{2}+\mathrm{Ct}^{3}+\mathrm{Ct}^{4}
\end{aligned}
$$

\section{Evaluation of models}

To assess the models used in this study, we computed the residuals after having estimated the parameters of the model. By definition, the residual is the difference between the actual data used for the estimation of the model coefficients and the corresponding predicted values derived from the model itself. The coefficiency of determination $r^{2}$ which indicates the proportion of the variance in the data explained by the model was used as a measure of goodness of fit.

\section{RESULTS}

Table 1 shows the results of the multiple regression analysis of monthly DTM against corresponding values of environmental temperatures, salinity, phytoplankton counts and $\mathrm{pH}$. Both the partial regression coefficient (Coef.) and the standard partial regression coefficients (Std. Coef.) are shown together with the standard error (std. error) of estimate. Additionally, tolerance (one minus the squared multiple correlation between each predictor and the remaining predictors in the equation) values are given. Tolerance values close to zero indicate that some predictors are highly intercorrelated; a situation which can lead to inflated standard errors of the regression coefficient, reduced associated $t$ statistic, and may even compromise computational accuracy. Our tolerance values indicate a lack of such multicolinearity. The standardised 
Table 1. Multiple Regression analysis of dry tissue mass (DTM) or condition index (dependent variable) against environmental temperatures (temp), salinity (sal), phytoplankton counts (phyto), and pH (independent variable). Var = variable; Coef = partial coefficient of multiple regression; Std Error = standard error of estimate, Std Coef $=$ Standard partial regression coefficient; Toler $=$ Tolerance; $r^{2}=$ coefficient of multiple determination; const $=$ constant .

(a) Dependent variable $=\mathrm{DTM}, \mathrm{N}=32, \mathrm{r}^{2}=0.613, \mathrm{P}<0.0005$

\begin{tabular}{lccccc}
\hline Var & Coef & Std Error & Std Coef & Toler & $P(2$ tail) \\
\hline Const. & -6.79 & 3.622 & 0.000 & - & 0.071 \\
Temp & 0.169 & 0.134 & 0.400 & 0.141 & 0.219 \\
Sal & -8.216 & 1.908 & -1.162 & 0.197 & 0.000 \\
Phyto & 0.000 & 0.000 & 0.171 & 0.374 & 0.389 \\
pH & 1.340 & 0.605 & 0.396 & 0.448 & 0.035 \\
\hline
\end{tabular}

(b) Dependent variable $=$ Condition index-1 $(\mathrm{Cl}-1), \mathrm{N}=32, \mathrm{r}^{2}=0.561, \mathrm{P}<0.0005$

\begin{tabular}{lrlrll}
\hline Var & \multicolumn{1}{l}{ Coef } & Std Error & Std Coef & Toler & $P(2$ tail) \\
\hline Const. & -9.973 & 7.856 & 0.000 & - & 0.215 \\
Temp & 0.283 & 0.292 & 0.329 & 0.141 & 0.340 \\
Sal & -15.879 & 4.138 & -1.104 & 0.197 & 0.001 \\
Phyto & 0.001 & 0.0001 & 0.164 & 0.374 & 0.438 \\
pH & 2.228 & 1.312 & 0.324 & 0.448 & 0.101 \\
\hline
\end{tabular}

(c) Dependent variable $=$ Condition index-2 $(\mathrm{Cl}-2), \mathrm{N}=32, \mathrm{r}^{2}=0.655, \mathrm{P}<0.0005$

\begin{tabular}{lrlrll}
\hline Var & \multicolumn{1}{c}{ Coef } & Std Error & Std Coef & Toler & $P$ (2 tail) \\
\hline Const. & -19.420 & 8.680 & 0.000 & - & 0.034 \\
Temp & 0.328 & 0.322 & 0.306 & 0.141 & 0.318 \\
Sal & -20.017 & 4.573 & -1.116 & 0.197 & 0.000 \\
Phyto & 0.001 & 0.001 & 0.231 & 0.374 & 0.221 \\
pH & 4.000 & 1.450 & 0.466 & 0.448 & 0.010 \\
\hline
\end{tabular}

partial regression coefficients are free of the original measurement scale, thus their magnitudes can be directly compared to show the relative standardised strengths of the effect of several independent variables on the same dependent variable (Sokal \& Rohlf, 1995). Ipso facto, it follows that of all the four environmental parameters tested, temperature has the most profound effect on DTM, followed by $\mathrm{pH}$ and phytoplankton counts, with salinity having the least effect. The comparatively low impact of salinity is understandable, since the water at the sampling station and throughout the range of distribution of the clam is freshwater $(<0.6 \mathrm{ppt})$ yearround. This order in relative importance of the different environmental factors is not changed even when DTM is replaced with $\mathrm{CI}-1$ as the dependent variable (Table 1a, b). But with
$\mathrm{Cl}-2$ as the dependent variable, $\mathrm{pH}$ exhibits the greatest impact (Table 1c).

There is a marked seasonal variation in the dry tissue mass and condition indices of the clam (Fig. 1). Table 2 shows that the fit of the basic sinusoidal model to each year's data was significant $(p<0.0005)$. Thus, the null hypothesis that the data is not a function of year is not accepted. Despite the monthly variation, the mesors $\left(\mathrm{M}_{\mathrm{o}}\right)$ (which are indicators of annual mean level) are similar. This implies a corresponding similarity in the inter-annual variation in factors which induces the tissue variation in the first instance. The fall in DTM and condition between June and October implies that the organism spawns during this period (Etim, 1990; Etim \& Taege, 1993).

The variation of the DTM or condition index with time was explained by a fit of the 
Table 2. Parameters of the basic sinusoidal model $Y=M o+A \cos 2 \pi t+B \sin 2 \pi t$ fitted to the monthly data on dry tissue mass (DTM). $M_{0}$ is the mesor which is annual mean of DTM, A and $B$ are empirical constants. $r^{2}$ is the coefficient of determination.

\begin{tabular}{lrlllll}
\hline Year & No. of months & M $_{0}$ & A & B & $r^{2}$ & P \\
\hline 1987 & 11 & 3.925 & -1.048 & 0.893 & 0.753 & $<0.0005$ \\
1988 & 12 & 4.243 & -1.57 & 0.059 & 0.808 & $<0.0005$ \\
1989 & 9 & 3.999 & -1.211 & 0.303 & 0.643 & $<0.0005$ \\
All years & 32 & 4.037 & -1.130 & 0.869 & 0.736 & $<0.0005$ \\
\hline
\end{tabular}

data to the one-compartment sinusoidal model whose coefficients were amenable to biological interpretation. Although the explained variance was higher when a two compartment sinusoidal model was employed (see $\mathrm{r}^{2}$ values in Fig. 1: a-1 and a-2), difficulties arise in imputing biological meaning to the coefficients. For instance, while the one compartment sinusoidal model carries a period of one year, the two compartment sinusoidal model implies a period of 6 months. The amplitude $h\left(=A^{2}+B^{2}\right)^{1 / 2}$ of the graph and the time $t_{o}(=1 / 2 p) \tan ^{-1}(B / A)$ when the maximum dependent variable occurs could easily be computed for the one compartment sinusoidal model. However, the biological interpretation of $t_{a}$, for instance, becomes difficult when the two compartment sinusoidal model is fitted to data.

Each of the three parabolic-based equations were highly significant (ANOVA: $\mathrm{P}<0.0005$ ). There is a gradual improvement in the value of $r^{2}$ as one moves from a fit of the data to the simple quadratic through the cubic to the quartic. And, as shown by visual inspection of the curves in Fig. 2, the predictive power of the model is also greatly enhanced with each term added to the basic quadratic model. However, this improvement of the fit as a consequence of an additional extra term to the basic model collapsed at the quintic model $\left(\mathrm{r}^{2}=0.348\right.$, graph not shown). Additionally, biological interpretation of these parabolic-based coefficients is not feasible.

\section{DISCUSSION}

There are more than twenty different types of condition indices used in both bivalve research and commercial practice. Depending on the variables used, condition indices can be classified into morphometric, biochemical or physiological (Mann, 1978). Alternatively, they can be classified either as static (determined at a single point in time), or dynamic (determined over a period of time to give information about physiological changes in the individual comprising the population) (Lucas \& Benninger, 1985). Many authors have proposed a 'standard' or 'recommended' index in an attempt to facilitate comparability of results. However, there is no consensus recommendation. For instance, Lawrence \& Scott (1982)

Fgure 1. Egeria radiata. (a-1) Observed monthly dry tissue mass (solid lines) of $E$. radiata with superimposed predicted values (broken lines) derived from the model DTM $=4.037+1.130 \cos 2 \pi t+0.869 \sin 2 \pi t, N=$ $32, r^{2}=0.736, P<0.0005$.

(a-2) Observed monthly dry tissue mass (solid lines) of $E$. radiafa with superimposed predicted values (broken lines) derived from the model DTM $=4.021+1.146 \cos 2 \pi t+0.896 \sin 2 \pi t+0.083 \cos 4 \pi t+0.246 \sin 4 \pi t$, $\mathrm{N}=32, \mathrm{r}^{2}=0.763, \mathrm{P}<0.0005$.

(b-1) Monthly variation in condition index-1 (CI-1) (solid lines) with superimposed predicted curve (broken line) derived from the one-compartment sinusoidal model CI-1 $=7.489-2.445 \cos 2 \pi t+I .536 \sin 2 \pi t, N=$ $32 ; r^{2}=0.734, P<0.0005$.

(b-2) Monthly variation in condition index-1 (CI-1) (solid line) with superimposed predicted curve (broken line) derived from the two-compartment sinusoidal model $\mathrm{Cl}-1=7.464-2.446 \cos 2 \pi \mathrm{t}+1.598 \sin 2 \pi \mathrm{t}+$ $0.440 \cos 4 \pi t+0.363 \sin 4 \pi t, N=32: r^{2}=0.764, P<0.0005$.

(c-1) Solid line shows the monthly changes in condition index-2 (CI-2) of $E$. radiata while broken line is the predicted value as derived from a one-compartment sinusoidal model CI-2 $=9.805-2.829 \cos 2 \pi \mathrm{t}+2.430$ $\sin 2 \pi \mathrm{t}, \mathrm{N}=32 ; \mathrm{r}^{2}=0.783, \mathrm{P}<0.0005$.

(c-2) Solid line shows the monthly changes in condition index-2 (CI-2) of $E$. radiata while broken line is the predicted value as derived trom a two-compartment sinusoidal model CI-2 $=9.741-2.911 \cos 2 \pi \mathrm{t}+2.517$ $\sin 2 \pi t+0.043 \cos 4 \pi t+0.959 \sin 4 \pi t, N=32 ; r^{2}=0.839, P<0.0005$. 

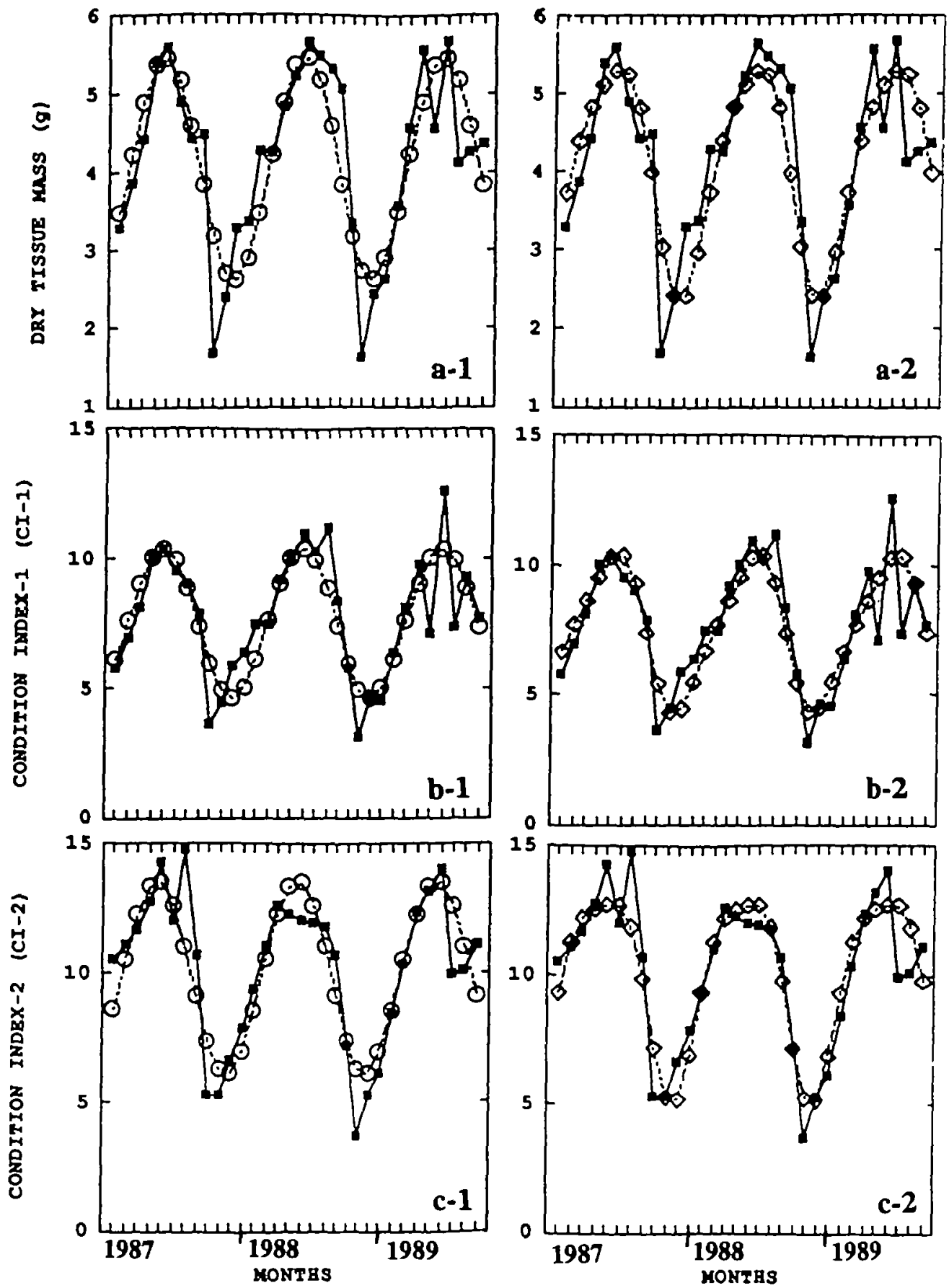
Figure 2. Egeria radiata. Monthly variation in dry tissue mass of $E$. radiata (solid lines) with superimposed predicted values derived from

(a) a quadratic model DTM $=3.531+6.821 \mathrm{t}-$ $8.448 t^{2}, N=32 ; r^{2}=0.548, P<0.0005$.

(b) a cubic model DTM $=1.713+24.029 t-47.412 t^{2}$ $+24.363 t^{3}, N=32 ; r^{2}=0.692, P<0.0005$.

(c) a quartic model DTM $=3.624-2.437 \mathrm{t}+$ $54.477 t^{2}-120.405 t^{3}+67.869 t^{4}, N=32 ; r^{2}=0.755$.

recommended 100 (dry meat weight)/(internal cavity volume) because the technique is simple and time efficient. Davenport \& Chen (1987) compared seven different indices and recommended 100(cooked meat weight)/(cooked meat weight + shell weight) because it was the most accurate and least variable. Beninger \& Lucas (1984) found a close correspondence between the Dry tissue weight/Dry shell weight and the Ash-free dry weight/Dry shell weight indices and suggested the use of the former which is more easily measured. Crosby \& Gayle (1990) compared three different indices of condition before recommending 1000 (dry soft tissue mass)/(internal shell cavity capacity) because it has fewer measuring errors, a lower coefficient of variation and is the easiest and fastest to use. Rainer \& Mann (1992) recommended indices based on volume and shell mass viz: 100 (dry meat weight)/(shell cavity volume); 100 (dry meat weight)/(dry shell weight). There are differences not only in the computation of condition index but also in the procedure for measuring the denominator and numerator. For example, there are about five different methods for measuring the internal volume of the bivalve: (a) the difference between the volume of water displaced by a whole live animal and that displaced by the shell, (b) the weight of a closed live bivalve in water is subtracted from its weight in air to have the total volume of the bivalve. The weight of the two shells in water is subtracted from the weight in air to give the volume of the shell material. Then the internal shell cavity volume is obtained as the difference between the total volume of the claim and the volume of the shell material (Quayle, 1950). This procedure is based on the Archimedes principle, (c) the shell cavity volume is also determined by subtracting the weight of the shell in air from the total weight of the whole animal in air (Lawrence \& Scott, 1982). The underlying principle here being that there is a $1: 1$ ratio between the cavity volume and the mass of its contents, (d) by noting the volume of water
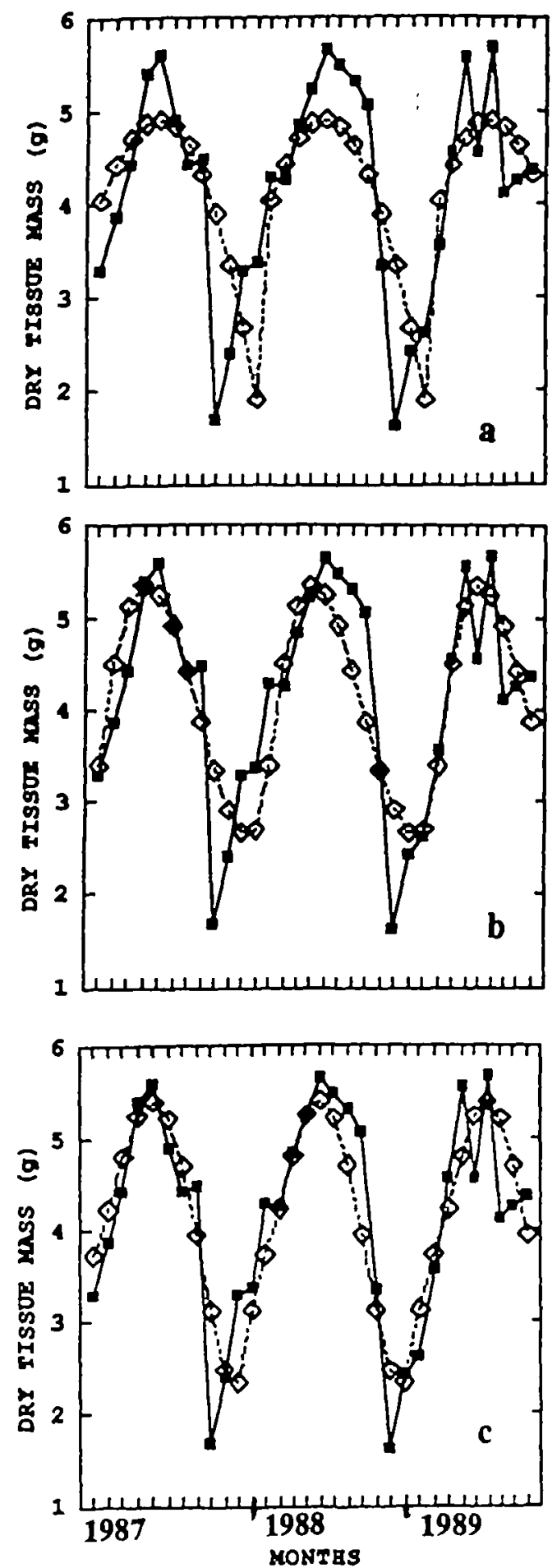
from a burette required to fill the two shell valves (Etim, 1990), (e) from the weight of sand that fills the two shells; given the density of the sand the weight could be converted to volume, (f) Emmett, Thompson \& Popham (1987) even used the volume of the whole animal instead of its internal volume. Since the precision and accuracy of each of these are not the same, inter-comparisons might not be valid. Crosby and Gale (1990) showed statistically that although condition indices employing (a) and (b) could be comparable, that employing shell weight as the denominator is different.

Condition index, which is assumed to be an indicator of the physiological state of the bivalve, is affected by many factors e.g. internal (state of gravidity, degree of parasitism, etc.) and external (temperature, salinity, food availability, etc.). Yet, all the different indices recommended as standards are based on ease of measurement, potential precision in measuring the components, and on statistical comparison of variance components, rather than on the innate sensitivity of the index to these factors that impact on the life of the bivalve itself. For instance, our results have shown that the 3 conditions used in this work are not equally sensitive to the same set of factors. While the seasonal variation in DTM indicates a dribble spawning (sensu Newell, Hilbish, Koehn \& Newell, 1982 and Schmitzer, Dupaul \& Kirkley, 1991) phenomenon during May 1989, the CI-2 indicates its occurrence in July 1987 and CI-1 does not seem to reflect such occurrence. Additionally, our multiple regression analysis shows that DTM and CI-1 are more affected by seasonal variations in temperature (Table 1a and b) while Table 1c shows that it is the $\mathrm{pH}$ that has the most profound effect on $\mathrm{CI}-2$. Thus these indices are intrinsically different; for while CI-2 measures the amount of space which the tissue could occupy, CI-1 gives an indication of the proportion of the total weight contributed by the shell and tissue.

\section{ACKNOWLEDGEMENTS}

The research tenure of Dr Etim (Institute of Oceanography, University of Calabar, Nigeria) at the Alfred Wegener Institute (AWI) is sponsored by the Alexander von Humboldt (AvH) Foundation, Bonn, Germany. The sponsorship from AvH and support from AWI are gratefully appreciated. Thanks to Paul $O$.
Etuk (Physics Department, University of Calabar, Nigeria) for discussions that were invaluable in crystallising seminal ideas in the development of initial concepts.

This is Alfred Wegener Institute Contribution number 1118.

\section{REFERENCES}

BATSCHELET, E. 1981. Circular statistucs in biology. Academic Press, London.

BENINGER, P.G. \& LUCAS, A. 1984. Seasonal variation in condition, reproductive activity and gross biochemical composition of two species of Adult Clam reared in a common habitat: Tapes decussatus L. (Jeffreys) and Tapes philippinarum (Adams \& Reeve) Journal of Experimental Marine Biology and Ecology, 79: 19-37.

Crosby, M.P. \& Gale, L.D. 1990. A review and evaluation of bivalve condition index with a suggested method. Journal of Shellfish Research, 9: 233-237.

Davenfort, J., Chen, X, 1987. A comparison of methods for the assessment of condition in the mussel (Mytilus edulis L). Journal of Molluscan Studies, 53: 293-297.

EmmetT, R., Thompson, K. \& Popham, J.D. 1987. The reproductive and energy storage cycles of two populatıons of Mytilus edulis (Linne) from British Columbia. Journal of Shellfish Research, 6: 29-36.

EтіM, L. 1990. Annual cycle of condition index and flood season spawning in the freshwater Donacid clam Galatea paradoxa (Born 1778) in Cross River, Nigeria. Tropical Freshwater Biology, 2: 233-240.

ETIM, L. 1996. Determination of reproduction cycle in a population of Egeria radiata (Lam 1804) (Bivalvia: Danacidae) using condition index and histological examination of gonads. Annales de Limnologle, 32: 105-113.

ETTM, L. \& BREY, T. 1994. Growth, productivity, and significance for fishery of the bivalve Egeria radiata (Donacidae) in the Cross River, Nigeria. Archives for Fisheries and Marine Research, 42: 63-75.

ETIM, L. \& TAEge, M. 1993. Comparison of condition indices and their seasonal variation in the freshwater clam Egeria radiata (Lamarck) (Tellinacea: Donacidae) from the Cross River, Nigeria. Aquaculture and Fisheries Management, 24: 602-612.

Grave, C. 1912. A manual of oyster culture in Maryland. Board Shellfish Commission of Maryland. 4th Rep. 279-348.

LAwRENCE, D.R. \& SCOTT, G.I. 1982. The determination and use of condition index of oysters. Estuaries, 5: 23-27.

Loesch, J.G. \& Evans, A.E. 1994. Quantifying seasonal variation in somatic tissue: Surf clam Spisula solidissima (Dillwyn, 1817) - A case study. Journal of Shellfish Research, 13: 425-431. 
Lucas, A. \& Beninger, P.G. 1985. The use of physiological condition indices in marine bivalve Aquaculture. Aquaculture, 44: 187-200.

MANN, R.A. 1977. Comparison of morphometric, biochemical, and physiological indexes of condition in marine bivalve molluscs. In: Energy and environmental stress in aquatic systems (J.H. Thorp \& J.W. Gibbons, eds), 484-497. Technical Information Centre. US Department of Energy.

Marcus, M., SCOTT, G.I. \& HeIZER, D.D. 1989. The use of oyster shell thickness and condition index measurements as physiological indicators of no heavy metal pollution around three coastal marinas. Journal of Shellfish Research, 8: 87-94.

Moses, B.S. 1990 . Growth, biomass, mortality, production and potential yield of the West African clam Egeria radiata (Lamarck) (Lamelibranchia: Donacidae) in the Cross River system, Nigeria. Hydrobiology, 196: 1-15.

NAIR, N.U. \& NAIR, N.B. 1987. Condition index and percentage edibility of Crassosstrea madrasensis (Preston) inhabiting the cochin Harbour. Fishery Technology, 24: 15-21.

Newell, R.1.E., Hilbish, T.I., KoEhN, R.K. \& NEWELL, R.C. 1982. Temporal variation in the reproductive cycle of Mytilus edulis L. (Bivalvia: Mytilidae) from localities on the east coast of United States. Biological Bulletin, 162: 299-310.

Press, W.H., Flannery, B.P., Teukolsky, S.A. \& VETTERLING, W.T. 1986. Numerical recipes: the an of scientific computing. Cambridge University Press, Cambridge.

PurChon, R.D. 1964. A note on the biology of Egeria radiara L. (Bivalvia: Donacidae). Proceedings of the Malacological Society of London, 35 251-275.

QUaYLE, D.B. 1950. The seasonal growth of the pacific oysters (Ostrea gigas) in Ladysmith harbour. British Columbia Department of Fisheries Report: 85-90.

RAINER, J.S. \& MANN, R. 1992. A comparison of methods for calculating condition index in Eastern Oysters, Crassossirea Virginica (Gmelın, 1791). Journal of Shellfish Research, 11: 55-58.

SASTRY, A.N. 1979. Pelecypoda (excluding Osteidae). In: Reproduction of Marine Invertebrates Vol. V. Molluscs, pelecypods and lesser classses. (A.C. Giese \& J.S. Pearse, eds) 113-292. Academy Press, New York.

Schmitzer, A.C., Dupaul, W.D. \& Kirkley, J.E. 1991. Gametogenic cycle of sea scallops (Placopecten magellanicus Gmelin 1791) in the mid Atlantic Bight. Journal of Shellfish Research, 10: $221: 228$.

SOKAL, R.R. \& ROHLF, F.J. I995. Biometry the principles and practice of statistics in biological research. 3rd Edition. W.H. Freeman \& Co. New York.

SYSTAT. 1992 Statistics. Version 5.2 Edition. Evanston, IL. SYSTAT Inc. 